\title{
Decoding of naturalistic textures from spike patterns of neuromorphic artificial mechanoreceptors
}

\author{
Alberto Mazzoni, Udaya B Rongala, Calogero M Oddo \\ From 24th Annual Computational Neuroscience Meeting: CNS*2015 \\ Prague, Czech Republic. 18-23 July 2015
}

Significant advances were recently achieved in the bidirectional control of upper limb neuroprostheses [1], however implementing a realistic tactile feedback on artificial hands is still an open challenge [2]. We target this ambition with a neuromorphic approach. Towards this direction we integrated MEMS tactile sensors with a realistic spatial arrangement on the distal phalanx of artificial fingers [3] and we converted the sensor readouts into spike trains mimicking the neural firing properties of glabrous skin mechanoreceptors [4]. The neuromorphic approach presents several advantages [5], among which the most relevant for neuroprosthetics is that a sufficiently realistic tactile feedback is expected to reduce drastically the time the brain needs to adapt to the prosthesis and to each single new task, leading to enhanced quality of life of the subjects.

Since the long term goal is to implement a hardware version of the neuromorphic neurons, we modeled the mechanoreceptors as Izhikevich neurons, a model which at the same time is computationally lean and takes into account the effects of firing rate adaptation that are particularly relevant in mechanoreceptors. Parameters were tuned so to achieve a match with Slowly Adapting (SA) mechanoreceptors dynamics in primates [4]. The output of each tactile sensor was normalized and injected as an excitatory input current into a single neuron model [6]. To reproduce the features of Fast Adapting (FA) mechanoreceptors responsible for edge detection [7], we injected in a second set of neuron models the smoothed derivative of the pressure sensors outputs.

The fingertip was then repeatedly presented with ten different daily-life textures such as textiles, polymeric

\footnotetext{
* Correspondence: a.mazzoni@sssup.it

The BioRobotics Institute, Scuola Superiore Sant'Anna, Viale Rinaldo Piaggio
} 34, Pontedera 56025, Pisa, Italy

\section{Acknowledgements}

by work was supported by the EU Grant FP7-FET 611687 NEBIAS project, The EU Grant FP7-NMP 228844 NANOBIOTOUCH project, by the Italian

Published: 18 December 2015

\section{References}

Raspopovic S, Capogrosso M, Petrini FM, Bonizzato M, Rigosa J, Di Pino G, Hand Prostheses. Science Translational Medicine 2014, 6(222):222ra219.

2. Kwok R: Neuroprosthetics: once more, with feeling. Nature 2013, 497(7448):176-177.

. Oddo CM, Controzzi M, Beccai L, Cipriani C, Carrozza MC: Roughness Encoding for Discrimination of Surfaces in Artificial Active-Touch. IEEE Transactions on Robotics 2011, 27(3):522-533.

4. Johansson RS, Flanagan JR: Coding and use of tactile signals from the fingertips in object manipulation tasks. Nat Rev Neurosci 2009, 10(5):345-59.

5. Service RF: Minds of their own. Science 2014, 346(6206):182-183. 
6. Izhikevich EM: Simple model of spiking neurons. IEEE Transactions on Neural Networks 2003, 14(6):1569-1572.

7. Spigler G, Oddo CM, Carrozza MC: Soft-neuromorphic artificial touch for applications in neuro-robotics. 2012 4th leee Ras \& Embs Internationa Conference on Biomedical Robotics and Biomechatronics (Biorob) 2012, 1913-1918.

8. Victor JD, Purpura KP: Nature and precision of temporal coding in visual cortex: A metric-space analysis. Journal of Neurophysiology 1996, 76(2):1310-1326

doi:10.1186/1471-2202-16-S1-P186

Cite this article as: Mazzoni et al:: Decoding of naturalistic textures from spike patterns of neuromorphic artificial mechanoreceptors. BMC

Neuroscience 2015 16(Suppl 1):P186

Submit your next manuscript to BioMed Central and take full advantage of:

- Convenient online submission

- Thorough peer review

- No space constraints or color figure charges

- Immediate publication on acceptance

- Inclusion in PubMed, CAS, Scopus and Google Scholar

- Research which is freely available for redistribution

Submit your manuscript at www.biomedcentral.com/submit
Ciomed Central 